\title{
Monthly hydrometeorological ensemble prediction of streamflow droughts and corresponding drought indices
}

\author{
F. Fundel, S. Jörg-Hess, and M. Zappa \\ Swiss Federal Institute for Forest, Snow and Landscape Research WSL, Zürcherstrasse 111, 8903 Birmensdorf, Switzerland \\ Correspondence to: F. Fundel (ffundel@gmail.com)
}

Received: 3 May 2012 - Published in Hydrol. Earth Syst. Sci. Discuss.: 1 June 2012

Revised: 9 November 2012 - Accepted: 24 November 2012 - Published: 29 January 2013

\begin{abstract}
Streamflow droughts, characterized by low runoff as consequence of a drought event, affect numerous aspects of life. Economic sectors that are impacted by low streamflow are, e.g., power production, agriculture, tourism, water quality management and shipping. Those sectors could potentially benefit from forecasts of streamflow drought events, even of short events on the monthly time scales or below. Numerical hydrometeorological models have increasingly been used to forecast low streamflow and have become the focus of recent research. Here, we consider daily ensemble runoff forecasts for the river Thur, which has its source in the Swiss Alps. We focus on the evaluation of low streamflow and of the derived indices as duration, severity and magnitude, characterizing streamflow droughts up to a lead time of one month.

The ECMWF VarEPS 5-member ensemble reforecast, which covers $18 \mathrm{yr}$, is used as forcing for the hydrological model PREVAH. A thorough verification reveals that, compared to probabilistic peak-flow forecasts, which show skill up to a lead time of two weeks, forecasts of streamflow droughts are skilful over the entire forecast range of one month. For forecasts at the lower end of the runoff regime, the quality of the initial state seems to be crucial to achieve a good forecast quality in the longer range. It is shown that the states used in this study to initialize forecasts satisfy this requirement. The produced forecasts of streamflow drought indices, derived from the ensemble forecasts, could be beneficially included in a decision-making process. This is valid for probabilistic forecasts of streamflow drought events falling below a daily varying threshold, based on a quantile derived from a runoff climatology. Although the forecasts have a tendency to overpredict streamflow droughts, it is shown that the
\end{abstract}

relative economic value of the ensemble forecasts reaches up to $60 \%$, in case a forecast user is able to take preventive action based on the forecast.

\section{Introduction}

Droughts, which can occur on a wide spatial and temporal range, can be defined in various ways. Typical and possibly interrelated processes are a temporally and spatially extended lack of precipitation (meteorological droughts), reduced soil moisture (agricultural droughts) and low levels of runoff or groundwater (hydrological droughts) (Heim Jr., 2002). This variety in the way droughts are defined is a direct consequence of the range of socioeconomic impacts they have on different interest groups. It is common to study the characteristics of low streamflow-related droughts on seasonal time scales (e.g., (Vidal et al., 2010)). However, streamflow droughts also appear on shorter time scales (Tallaksen et al., 1997). Some of the short, consecutive events might be connected to one prolonged drought; nevertheless they can cause damage to certain susceptible sectors and are worthwhile to consider individually. Streamflow drought forecasts on time scales up to one month are potentially useful for hydro-power generation, agriculture (irrigation), conventional power production (supply of heat exchange water), water quality, navigation (shipping) and tourism (e.g., water supply for snow cannons), in general, all sectors that can use the information about upcoming streamflow drought events to take preventive action. For those sectors, skilful forecasts of streamflow droughts could help to prevent or mitigate the consequences of a water shortage (Steinemann, 2006). 
Generally, two approaches to predict properties of low streamflow events in the long range can be discerned. First, stochastic approaches that relate the current state of a catchment and potential predictors to what has been observed in the past, to infer the likelihood of low streamflow within the prediction period. These include regression techniques (Moreira et al., 2008; Cebrián and Abaurrea, 2011; van Ogtrop et al., 2011), time series models (Lohani and Loganathan, 1997; Chung and Salas, 2000; Mishra and Desai, 2005; Bordi and Sutera, 2007), and neural network techniques (Kim and Valdés, 2003; Mishra and Desai, 2006; Morid et al., 2007). Also procedures identifying correlations of drought events with teleconnection patterns (Tadesse et al., 2005; Özger et al., 2012) or certain weather types (Fleig et al., 2011) can be used to indicate potential drought events. Cancelliere et al. (2006) and Hwang and Carbone (2009) used autoregressive models not only to predict drought indices but additionally to quantify the uncertainty of their prediction. Drought indices inferred from statistically downscaled atmospheric models (Cacciamani et al., 2007) also have proven predictive quality.

The second, less common approach for the long-range prediction of droughts involves a coupled atmospherichydrological model. Wood et al. (2002) employ monthly forecasts from a global atmospheric model to drive a gridbased hydrological model that produces reasonable predictions of low streamflow up to several months in advance. The refined systems of Li et al. (2008) and Luo and Wood (2007) were able to predict average monthly drought conditions up to three months ahead.

In this study, we assess the quality of forecasts of hydrological droughts, characterized by low streamflow, for a lead time of up to one month. Streamflow is an appealing measure for droughts as it combines different catchment aspects, ranging from the input of precipitation to storage and transfer processes. By coupling or forcing hydrological with meteorological models, useful peak-flow predictions for a shorter forecast range are possible. As the predictability of an event mainly depends on its lifetime (Hirschberg et al., 2011), peak-flow forecasts rarely show skill beyond 10 days. This, however, depends on the catchment characteristics, as well as the quality of the models involved and the observations needed for an appropriate initialization (Webster et al., 2010; Fundel and Zappa, 2011). Streamflow droughts on the other hand are generally rather persistent phenomena. This is why predictions could potentially still be valuable in the longer range. It might therefore be worthwhile investigating their properties at lead times long after peak-flow predictions have lost their value. The value of forecasts can be increased if additionally the prediction uncertainty is quantified, e.g., by using a meteorological ensemble prediction system (EPS) or a multi-model ensemble (Cloke and Pappenberger, 2009) or multiple hydrological models maybe applying different model parameterizations (Rings et al., 2012).

This study introduces several new aspects of forecasting streamflow droughts such as, compared to existing studies on streamflow drought, a high temporal resolution and an ensemble approach to include forecast uncertainty. Daily predictions of streamflow drought up to a lead time of one month, employing the VarEPS ensemble reforecast (Vitart et al., 2008b) from the European Centre for Medium-Range Weather Forecast (ECMWF) as forcing for the hydrological model PREVAH (Viviroli et al., 2009), are assessed. Compared to the above-mentioned studies on the prediction of hydrological droughts, a higher temporal resolution is examined. The daily mean catchment runoff forecasts of 32-day lead time were produced in the period from 1991-2008, providing a large sample size and hence a robust estimation of forecast value. A further new aspect is the evaluation of forecasts regarding the lower end of the flow regime by considering indices describing low streamflow scenarios, namely duration, severity and magnitude. Below normal levels of streamflow can have socioeconomic impacts at all times of the year, also in seasons that are generally not associated with water shortages. To address this, a daily varying threshold based on past observations of streamflow is used to indicate streamflow droughts. Compared to monthly average forecasts of drought indicators, the here considered forecasts could be potentially useful for a new group of users, especially forecast users that are affected by short events and users that can take preventive action having a relatively short warning lead time. To estimate the value for a variety of users, the resulting forecasts are evaluated in terms of their economic value.

\section{Data and methodology}

\subsection{Domain}

The domain chosen for this study is the pre-alpine catchment of the Thur River located in the north-eastern part of Switzerland. The Thur River has a length of $127 \mathrm{~km}$ and discharges into the Rhine River. The catchment is $1696 \mathrm{~km}^{2}$ in area, and its vertical extent is from 356 at the gauging station in Andelfingen to $2503 \mathrm{~m}$ a.s.l. at the top of the Säntis. The mean altitude is $769 \mathrm{~m}$ a.s.l.; $25 \%$ of the catchment lies above $1000 \mathrm{~m}$ a.s. 1 and $0.6 \%$ above $2000 \mathrm{~m}$ a.s.l. The submontane climate is relatively cool, and the runoff-generating processes from autumn to spring are affected by snowfall and melt processes. The annual average precipitation amount is about $1500 \mathrm{~mm}$ and mainly falls during the summer months. Figure 1 shows the monthly catchment average temperature mean and precipitation sum in the study period 1991-2008. Due to the vertical extension of the catchment topography, the values can differ largely within the catchment. Average values of other meteorological variables and their height distributions are given in Gurtz et al. (1999). Figure 2 (left) shows some lower quantiles of catchment runoff, measured at the gauging station in Andelfingen from 1991-2008 using a gliding window of 31 days centered on the date of 


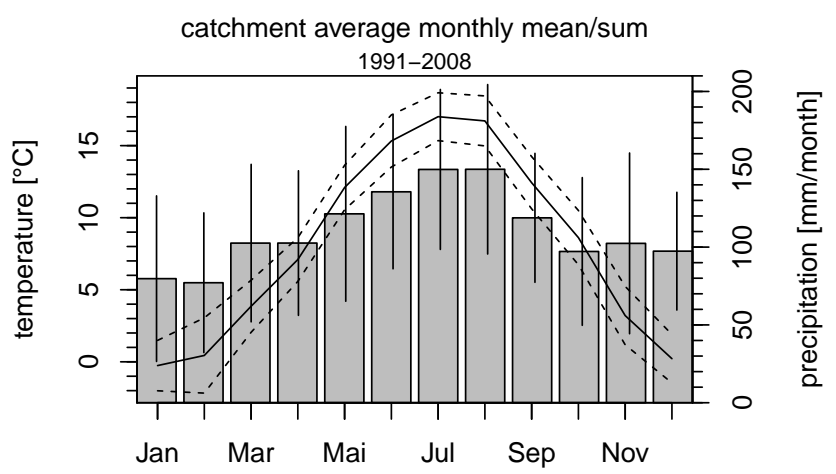

Fig. 1. Thur catchment average mean monthly temperature (solid line) and precipitation sum (bars) in the study period 1991-2008. The dashed lines and vertical bars show one standard deviation.

interest. The maximum of runoff in April can be attributed to snowmelt. The runoff minima from September to February, depending on the considered quantile, are caused by the combination of less precipitation and snow accumulation.

This catchment, which is relatively large for Alpine conditions, was chosen as in smaller catchments streamflow drought rarely occurs over a longer period. In small catchments, low streamflow events are easily interrupted by smallscale precipitation events, which complicates the evaluation of longer-lasting events. A large catchment is therefore thought to be more appropriate to demonstrate the forecast value for longer events happening within the range of one month. Besides that, the runoff regime is relatively unaffected by human influences; i.e., no reservoirs or weirs are installed (Gurtz et al., 1999) that could potentially alter the runoff during periods of low streamflow.

\subsection{Meteorological forcing}

The unified variable resolution ensemble prediction system VarEPS (Vitart et al., 2008a,b) operated by the ECMWF produces each week a global, 51-member forecast with a lead time of 32 days. Its horizontal resolution is $50 \mathrm{~km}$ for the first 10 days and $80 \mathrm{~km}$ in the remaining 11-32 days. From day 10 onwards, the atmospheric model is coupled to an oceanic model. The motivation for varying the resolution is to benefit from the higher resolution in the early forecast range at longer lead times. At the time of this study, the forecasts were issued for Thursday at 00:00 UTC and were archived in timesteps of $6 \mathrm{~h}$.

With each run of the operational VarEPS, an ensemble reforecast is started for the same day of the year over the past $18 \mathrm{yr}$, and also ranges over 32 days. The reforecasts share the same model version as the forecasts and are meant to capture the same model errors, e.g., to allow for an efficient post-processing, a more robust evaluation of forecast skill and a more target-oriented model development. The VarEPS reforecast dataset consists of $954(18 \mathrm{yr} \times 53$ initializations per year) ensemble forecasts. Unlike the operational forecast, the reforecasts have 5 ensemble members only, initialized with states taken from the ECMWF global reanalysis ERAInterim or from ERA40. More detailed information about the history of model developments is available at http://www. ecmwf.int/products/data/technical/model_id/index.html.

For this study the VarEPS 5-member reforecast is used to drive the hydrological model. Fields of wind speed, $2 \mathrm{~m}$ temperature, $2 \mathrm{~m}$ dew point, sunshine duration, surface albedo and solar radiation are required as input. To meet the grid size of the hydrological model of $500 \mathrm{~m} \times 500 \mathrm{~m}$, a downscaling was performed, based on a bilinear interpolation (Gurtz et al., 1999; Viviroli and Gurtz, 2007). Temperature was adjusted according to elevation, assuming a lapse rate of $0.65^{\circ} \mathrm{C} / 100 \mathrm{~m}$ (Jaun and Ahrens, 2009).

\subsection{Hydrological model}

Runoff predictions were generated using the semi-distributed hydrological model Precipitation Runoff EVApotranspiration Hydrotope (PREVAH, Viviroli et al., 2009), with VarEPS as the meteorological forcing. PREVAH consists of hydrological response units (HRUs) and a runoff generation module based on the HBV model (Bergström and Forsman, 1973), taking account of the spatial distribution. Information on PREVAH physics and the parameterization is given in Gurtz et al. (1999) and Viviroli and Gurtz (2007). PREVAH's parameter setting was conditioned by matching the produced runoff to observed runoff at the gauging station in Andelfingen for the period from 1995-2000. This optimization was performed with a focus on the average flow volume. PREVAH runs in hourly time steps. For this study, however, only daily mean runoff is considered. The setup of PREVAH adopted for the Thur basin is the same as the one used in Fundel and Zappa (2011) and Zappa and Kan (2007). In the latter publications the calibration and verification of the modeled runoff against the observed runoff, the water balance components, and hydrographs are presented.

Initial conditions for each forecast run were obtained from a continuous reference simulation forced with meteorological surface observations from 12 measurement sites, 6 within and 6 outside a distance of $100 \mathrm{~km}$ to catchment. The initial states contain information about the water storage in the different modules of each HRU. To highlight the quality of the initial conditions, Fig. 2 shows a comparison of the reference simulation and the runoff observed at the gauging station in Andelfingen for the low runoff regime. The seasonal cycle and the runoff volume concur well. The evaluation of daily mean runoff from the reference simulation during the study period 1991-2008 results in a mean error of $-0.003 \mathrm{~mm} \mathrm{~h}^{-1}(-3 \%)$, a Nash-Sutcliffe coefficient (Nash and Sutcliffe, 1970) of 0.87 respectively 0.88 using logarithmized runoff.

When investigating forecasts of observations of hydrological droughts, a smoothing or pooling algorithm, spanning 

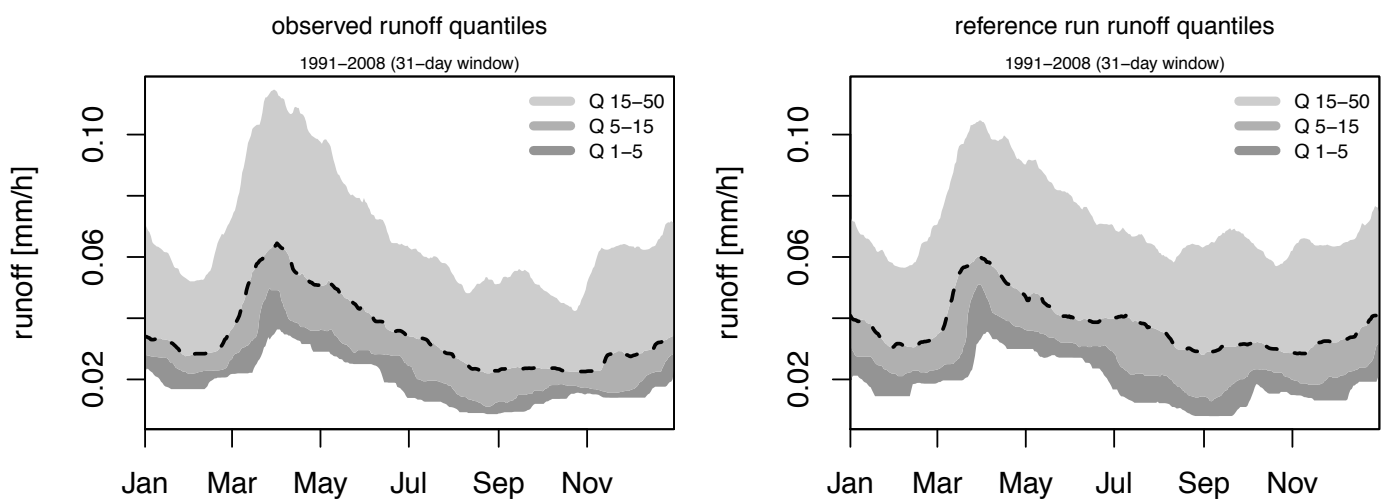

Fig. 2. Lower runoff quantiles for the Thur catchment from gauge measurements (left) and the hydrological reference run (right). The quantiles were calculated for daily mean runoff and non-exceedance probabilities of $1 \%, 5 \%, 15 \%$ (dashed line) and $50 \%$, utilizing a window of 31 days around the day of interest.

several days, is often applied to the data in order to avoid counting several short events that belong to the same largerscale drought. Here, however, no further smoothing of the daily forecasts is applied, mainly in order to evaluate the predictive capability of the hydrometeorological prediction system that has the potential to simulate short-term variability in runoff but also due to the fact that shorter events of abnormally low streamflow can lead to economic losses as well.

\subsection{Characterization of hydrological droughts}

Streamflow droughts are generally characterized by the indices duration (time between onset and offset), severity (cumulative water deficit) and magnitude (severity/duration) (Tallaksen et al., 1997; Hisdal and Tallaksen, 2000; Hisdal et al., 2001; Smakhtin, 2001; Zaidman et al., 2002; Fleig et al., 2006; Nalbantis and Tsakiris, 2008; Mishra and Singh, 2010; Yoo et al., 2011). Defining hydrological droughts solely by considering those indices requires the assignment of a runoff threshold. Whenever the predicted or observed runoff falls below that threshold, this counts as an event of streamflow drought. Figure 3 illustrates the streamflow drought indices drawn from an observed or forecast hydrograph, with indices being dependent on the choice of the threshold. It is, however, not obvious where the threshold should be set. Some stakeholders sensitive to low streamflow may be interested in a constant threshold, e.g., a power plant that requires a certain amount of water for cooling. Others might be affected by droughts only in certain seasons, e.g., tourism. To meet both concerns, a variable, quantile-based streamflow drought threshold was selected. The threshold was calculated individually for each day of the year, using runoff from the 18-yr study period and a gliding 31-day window around the date of interest. This implicates that events are classified as streamflow drought in parts of the year associated with higher runoff, which would not be considered as streamflow drought events in other, drier parts of the year. However, in this study streamflow drought is interpreted as

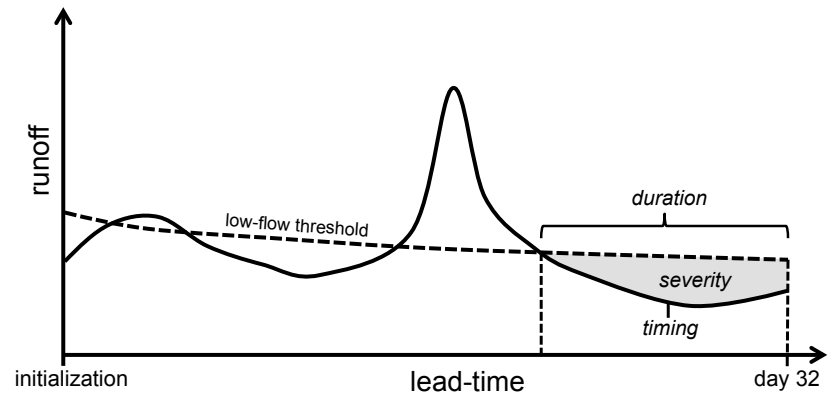

Fig. 3. Illustration of the streamflow drought indices considered in this study. The solid line is the observed or forecast runoff, i.e., in certain periods, above or below the streamflow drought detection threshold (dashed line). For each forecast member of each 32-day forecast and the corresponding observation, the longest consecutive period below the threshold (streamflow drought duration) is evaluated. The water deficit during this period (severity, shaded area) is the cumulative difference between the threshold and runoff. The quotient of severity and duration, called magnitude, is evaluated as well. Timing is defined as the moment when half of the event has happened.

exceptionally low with respect to what is expected in a certain part of the year. The actual quantile chosen for the varying threshold is selected later, based on the quality of the forecasts of derived streamflow drought indices and the robustness of the results.

In addition, the quantile-based threshold was calculated separately for observed and forecast runoff, using either an observation climatology or a climatology assembled of past forecasts. This is a very simple way to correct for systematic additive error (bias) in runoff forecasts. Using the same threshold for observations and forecasts would possibly result in a systematic over- or under-forecasting of streamflow drought events. By choosing separate thresholds for observed and for forecast runoff based on the same frequency of occurrence, we can assure this bias will not affect the 
verification results of streamflow drought duration. Possible nonlinearities in the prediction bias could, however, influence the verification results of streamflow drought severity and magnitude. Besides that, the forecast error could vary with lead time. Therefore, a lead time dependency of the streamflow drought threshold was implemented by deriving the threshold from a climatology of forecasts stratified by its lead time. After all, a bias could be removed by, e.g., statistical post-processing. However, well-calibrated forecasts of rare events require a large training dataset, which is why this simple method is preferred.

Within the 32-day forecast range, the events of observed or forecast runoff falling below the streamflow drought threshold were detected and the streamflow drought indices were calculated. In addition to that, the timing of each streamflow drought event was calculated as the center time between onset and end of an event. If more than one event was detected within a forecast interval of 32 days, the longest consecutive period of low streamflow was considered as the forecast/observed event. Forecast and observed events do not necessarily have to overlap, neither between forecast and observation nor between the ensemble forecast members. The forecast system is reduced with the objective to answer the following questions: what is the longest expected streamflow drought event within the next 32 days and was such an event observed? In the case of probabilistic forecasts, the question is different: what is the probability of exceeding a streamflow drought event of $x$ days duration ( $y \mathrm{~mm}$ severity; $y / x \mathrm{~mm} \mathrm{day}^{-1}$ magnitude) within the next 32 days? By doing so, an imprecise timing of the forecast low streamflow event does result in a less strong degradation of the verification score. For events truncated by the limited forecast range of 32 days, an influence on the verification score caused by deficiencies in forecast timing cannot be excluded. In the here used forecast data, $29 \%$ of the events are still prevalent at the end of the forecast range at day 32 .

Duration, severity and magnitude of streamflow droughts are clearly not independent as they are all calculated from the same set of events. For example an event of long duration is likely to be very severe as well. Their forecast performances are therefore expected to be similar. Still, the different indices should reflect the demands of different interest groups to a streamflow drought forecast. For hydro-power production, for example, the severity might be of paramount interest, whereas for power-plant cooling the duration is more crucial.

\subsection{Verification scores}

The focus of the verification of ensemble streamflow drought index forecasts is set on the value they have for potential forecast users. A score, designed to give the value of a forecast depending on the vulnerability of a forecast user to a certain event, is the relative value or value score (Murphy, 1977; Richardson, 2000; Roulin, 2007). The user is supposed to take preventive action whenever a forecast is issued with a probability exceeding the user's personal cost-loss ratio. Loss is the customers expense when being struck by an event without any preparation. Cost is what the user would spend on taking preventive action. The value score then gives the relative economic gain for the user when following the advice of the forecast, compared to having only the climatological event frequency as a basis for decision-making. The value score varies between $\leq 0$ (no additional forecast value) and 1 (perfect forecast). Note that even if the value score equals 1 , the user still has to bear the costs for taking preventive action. The value score is calculated for probabilistic forecasts of exceeding a threshold. It gives a value for each possible probability the prediction system can issue, depending on the cost-loss ratio. The upper envelope of all value curves gives the value of the prediction system.

Another score, designed to give an intuitive measure of the prediction system performance, is the generalized discrimination score, or two alternatives forced choice score (2AFC) (Mason and Weigel, 2009; Weigel and Mason, 2011). The score is based on pairs of observations and forecasts. It reflects the forecast performance in discriminating between different observations. An appealing property of the score is its applicability for ensemble, probabilistic, dichotomous, polychotomous or continuous forecasts and corresponding observations. Here, as an illustration, we give the formulation for probabilistic forecast; for all other possible combinations of forecast and observation type, referred to Mason and Weigel (2009) and Weigel and Mason (2011). Let $n_{1}$ be the number of observed events $i, n_{0}$ the number of nonevents $j$. With $p_{1, j}$ respectively $p_{0, i}$ as forecast probabilities for events that respectively did not occur, the $2 \mathrm{AFC}$ score is calculated as

$2 \mathrm{AFC}=\frac{1}{n_{0} n_{1}} \sum_{i=1}^{n_{0}} \sum_{j=1}^{n_{1}} I\left(p_{0, i}, p_{1, j}\right)$

applying the rule

$I\left(p_{0, i}, p_{1, j}\right)=\left\{\begin{array}{l}0.0 \text { if } p_{1, j}<p_{0, i} \\ 0.5 \text { if } p_{1, j}=p_{0, i} \\ 1.0 \text { if } p_{1, j}>p_{0, i}\end{array}\right.$

A $2 \mathrm{AFC}$ score above $50 \%$ is reached if the forecast is better than a guess based on climatology, hence skilful, assuming that the forecast/observation sample is representative for the climatological regime. A perfect forecast scores $100 \%$. The 2AFC score gives an intuitive measure of the frequency of correct forecasts. Here, the 2AFC score is used to evaluate ensemble predictions against observed runoff, or probabilistic predictions (probabilities to exceed a threshold) against dichotomous (i.e., $\in\{0,1\}$ ) observed outcomes, depending on the context. 

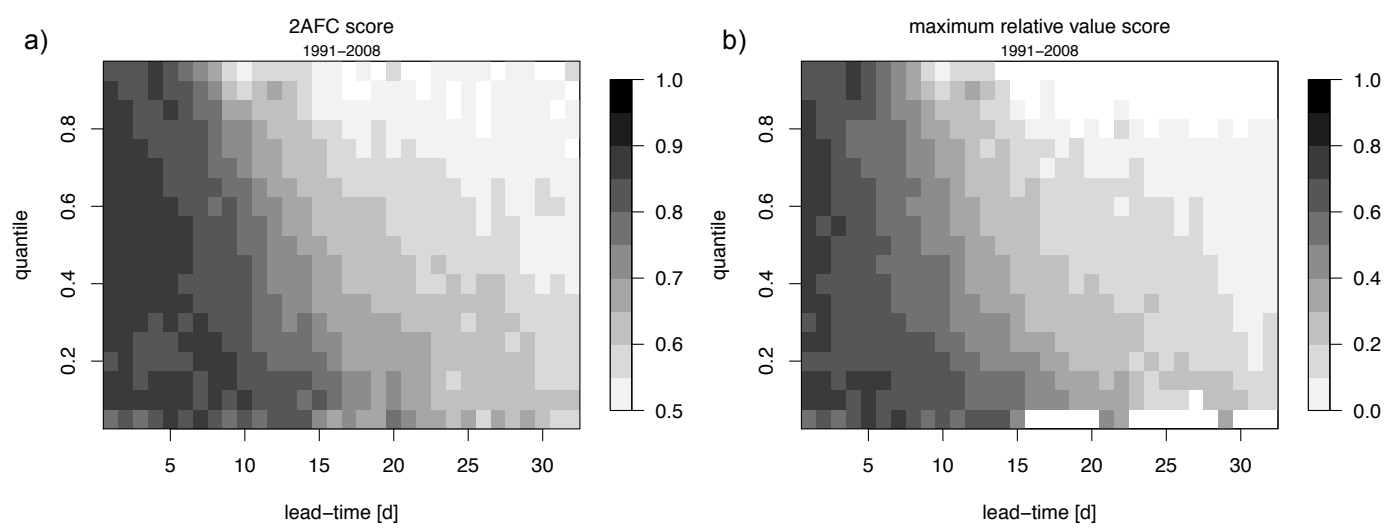

Fig. 4. 2AFC and maximum relative value scores for the Thur VarEPS/PREVAH daily mean runoff forecasts up to a lead time of 32 days. In the study period 1991-2008, probabilities of the ensemble forecasts to exceed different, quantile-based, varying thresholds are verified.

\section{Results}

In this section, the forecast quality for different flow regimes is evaluated on a daily basis as well as for scenarios described by the streamflow drought indices. This comprises the choice of a daily varying streamflow drought detection threshold and the assessment of the quality and impact of the initial conditions. The economic value of streamflow drought index forecasts is given for different interest groups.

\subsection{Extended lead-time forecast quality}

One basic hypothesis of this study is the better predictability of low streamflow events than peak-flow events. As a consequence, longer range forecasts of streamflow droughts should prove useful for end users. To back up this hypothesis, it is tested how well the forecast system can predict the probability to exceed different thresholds, from very low to very high runoff, depending on the forecast lead time. A number of ascending quantiles from the complete gauged Thur runoff time series available are used as thresholds. The thresholds are, as described in Sect. 2.4, calculated on a daily basis. Some of the lower quantiles can be seen in Fig. 2. Figure 4a shows the 2AFC score for forecast probabilities to exceed these thresholds for lead times from 1 to 32 days. The results support the hypothesis. Peak flow forecasts, i.e., exceedance probabilities for the 80th quantile and above, show very little to no skill past about day 15 . In contrast, probabilistic low streamflow forecasts, e.g., for the 20th quantile, are skilful up to the end of the forecast range. At low thresholds, the forecast quality decreases less rapidly with growing lead time. A very similar picture is obtained when using the relative value score. Figure $4 \mathrm{~b}$ shows the maximum of this score for any cost/loss ratio. Peak-flow forecasts show no relative value past a lead time of 15 days, whereas probabilistic forecasts of low streamflow are valuable over the entire forecast range. Relative values greater than 0.6 are possible up to a lead time of 15 days and more than 0.1 at 32 days. For both plots in Fig. 4, not significantly skilful score values are colored white. This was tested by resampling the underlying verification data 1000 times with replacement and applying a t-test with a confidence level of 0.95 to see whether the score mean was significantly larger than the smallest value considered as skilful.

The long-term predictability of streamflow drought events might be attributed to the persistence of the initial state of the model. Conceptually, the recession rate of streamflow is a function of the streamflow itself (e.g., Kirchner, 2009). The lower the streamflow, the slower any further reduction occurs. Consequently, a good initialization of the prediction model is especially crucial for forecasts of streamflow drought events. If the initialization leads to a surplus of runoff, for example, the streamflow drought threshold might not be crossed within the forecast range or, at least, the forecast timing would be poor.

The dependence of forecast quality (in terms of the 2AFC) on the quality of the initial state for high and low runoff regimes is shown for lead times from 1-32 days in Fig. 5. The plot shows the $90 \%$ confidence limits (from $5 \%$ to $95 \%$ ) found by random resampling of the dataset 1000 times with replacements. As no observations for the initial state variables are available, the separation between good and poor initial states is based on runoff. It is assumed that a good initial state, provided by the reference run, results in a predicted runoff close to the observed runoff. Hence, the difference in runoff between both is taken as a measure for the quality of the initial state. In order to get a clear signal, we consider an initial state as good if the predicted runoff at initialization deviates less than $25 \%$ from the observed runoff, and as poor if it deviates more than $75 \%$. For both groups lowand high-flow regimes are considered separately by verifying the probability of daily runoff to exceed the 85th and the 15 th quantile. In the low runoff regime, a good initial state can contribute to forecast skill over the complete forecast range of one month. The effect of a good initialization on the 


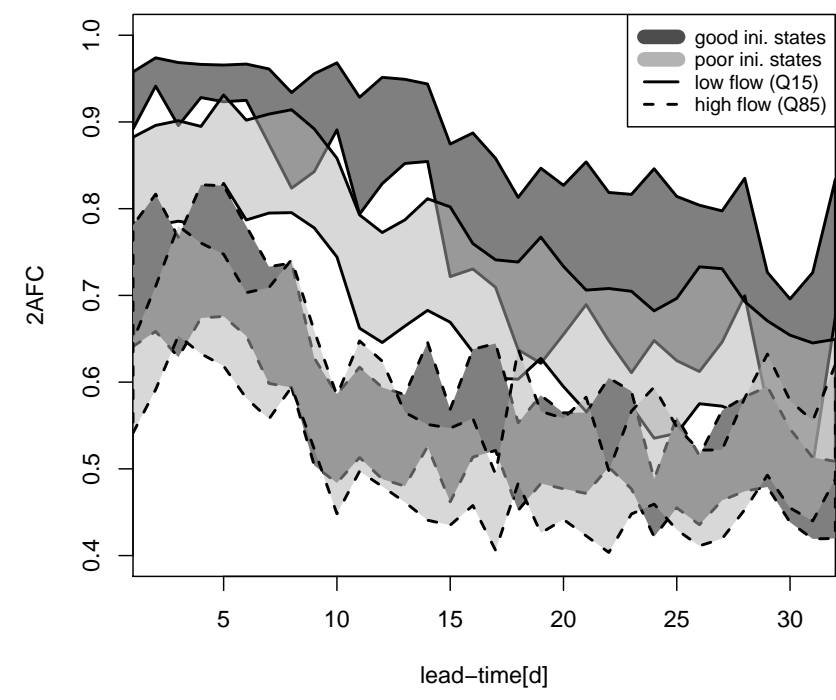

Fig. 5. 2AFC scores of probabilistic VarEPS/PREVAH daily runoff forecasts for different lead time ranges, different exceedance thresholds and different initial states qualities. The polygons show the $90 \%$ confidence interval, found by resampling 1000 times.

forecast of higher runoff is lost after about one week. This illustrates the importance of a good initialization, especially in the context of forecasting streamflow drought events.

\subsection{Choice of the streamflow drought detection threshold}

To proceed from forecasts of daily runoff to forecasts of streamflow drought indices, a threshold needs to be selected. Therefore, the performance of low streamflow index ensemble predictions, according to the choice of thresholds used to define a streamflow drought event, is evaluated next. The result of this analysis should give an indication about which threshold would be most appropriate for the subsequent verification of the streamflow drought index forecasts. Figure 6 shows the verification results of ensemble duration, severity and magnitude forecasts for streamflow drought detection thresholds from the varying 5th to 50th quantile of Thur runoff. The boxes indicate the range and inter-quartile range found by 1000 times random resampling of the dataset. For all indices, the overall forecast performance appears to be better if a lower threshold is chosen. Duration forecasts degrade most strongly with higher thresholds, but stay skilful with a $2 \mathrm{AFC}$ score of $67 \%$ when using the 50th quantile. Severity forecasts reach a $2 \mathrm{AFC}$ score of about $70 \%$ for the 50th quantile, and the magnitude forecast skill stays constant at about $72 \%$ within the uncertainty bounds when varying the threshold. The decrease in forecast skill with increasing threshold can be attributed to the enlarged uncertainty in the forecast itself. The higher uncertainty about the score at lower thresholds is a result of the lower number of events. For the subsequent evaluation of streamflow drought index forecasts, a threshold based on the varying 15th quantile is applied, resulting in 529 events detected for 954 ensemble forecasts (Fig. 6). The choice of the 15th quantile is a compromise between the number of streamflow drought events and the significance of the findings regarding low streamflow. The runoff associated with the 15th quantile, i.e., the streamflow drought detection threshold used for our research catchment, can be deduced from Fig. 2. A distinct seasonal runoff maximum occurs in April due to the contribution of snowmelt. The yearly minimum is reached in October or November, when snow accumulation starts.

\subsection{Streamflow drought indices prediction/observation}

As already shown, the quality of a streamflow drought forecast relies greatly on the quality of the representation of the catchment initial state in the hydrological model. This initial state is taken from a reference run, forced with meteorological surface observation. Usually, without having measurements of the state variables of hydrological models available, one way to infer the quality of the initial state is to look at a good reproduction of runoff by the reference run. Figure 7 shows the occurrence (therefore indirectly the duration), severity and magnitude of streamflow drought events at the runoff gauge in Andelfingen during the study period 1991 to 2009, as observed or predicted by the reference run. As a streamflow drought detection threshold of varying quantiles is used, the events are distributed evenly over the year. The most severe events and the events of greater magnitude however mostly occur in late spring/early summer, when the runoff reaches the yearly maximum due to the contribution of melting snow. The high quality of the reference run already mentioned is also reflected in its representation of the streamflow drought indices. A high degree of agreement between observation and reference can be seen in the occurrence and timing of the events. High severities and magnitudes in the observations are also strong events in the reference run, although the absolute number can vary. Altogether, the initial states seem to provide a reasonable basis for the initialization of forecasts.

Ensemble forecasts of streamflow drought duration, severity and magnitude, utilizing a threshold based on the varying 15th quantile of runoff, are shown in Fig. 8 together with the corresponding observations. The plot shows the range of the weekly started forecast streamflow drought indices, valid for the next month. To enhance readability the observed indices and the forecast ranges are concatenated. Duration and severity of the observed streamflow drought are contained well within the range of the ensemble, although it appears that the forecasts have a tendency to overpredict the events. The characteristics of duration, severity and magnitude forecasts are very similar to each other as they are derived from the same streamflow drought events. Note that, due to the weekly start of the forecast, each day is covered by three forecasts. A very long event is therefore captured by several forecast. For some 
Quality of low-flow index ensemble forecasts 1991-2008 $1991-2008$

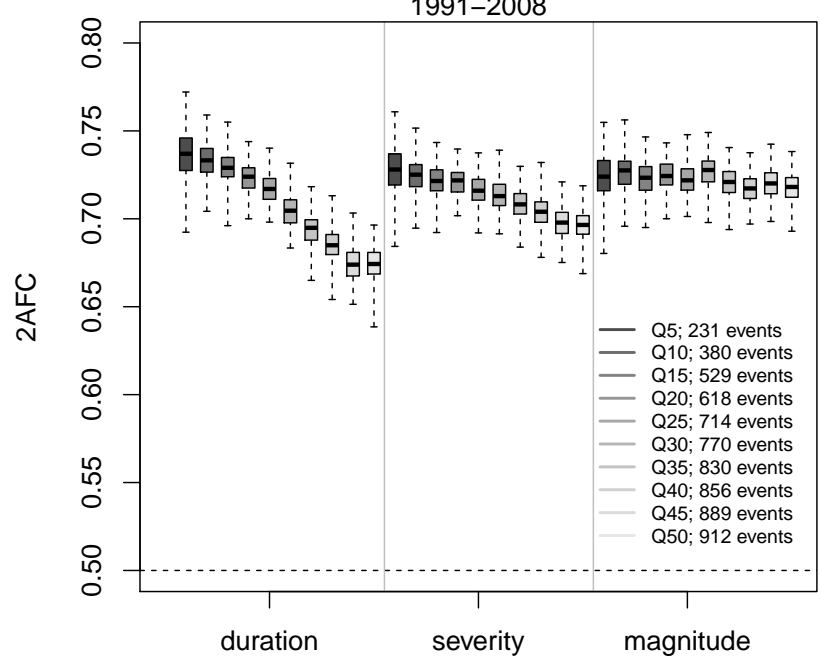

Fig. 6. Overall performance of duration, severity and magnitude ensemble forecasts, subject to the chosen streamflow drought detection threshold for the Thur catchment. The boxes indicate the range, inter-quartile range and median of the $2 \mathrm{AFC}$ score, found by resampling the forecast in the verification period 1000 times. The number of observed streamflow drought events for each threshold is given in the legend.

forecasts such an event can exceed the forecast range, or a forecast might start during an event. As in observation and reference run, the occurrence of streamflow drought events is distributed equally over the year in the forecasts, which was expected as the detection threshold varies with season. One noticeable feature that can be seen in the ensemble forecasts and the observations is the distinct signal left by the 2003 drought caused by a heat wave that affected large parts of Europe (Beniston, 2004; Schär et al., 2004; Zappa and Kan, 2007).

The first impression of over-forecasting is confirmed by the rank histograms (Talagrand et al., 1997) in Fig. 9. A disproportionately large part of observations fall in the lower bins spanned by the ensemble members. This lack of reliability is most distinct for magnitude forecasts, and less for forecasts of duration and severity. However, the discrepancy between the forecast probability and the observed frequency is a type of error that could possibly be corrected for with a statistical post-processing. Such a model bias was partly corrected for by using separate detection thresholds for observations and for forecasts.

\subsection{Relative economic value}

The economic value of probabilistic forecasts of streamflow droughts, exceeding different levels of duration, severity and magnitude was calculated for forecast probabilities using the 15th quantile streamflow drought detection threshold (Fig. 10). Value scores $>0$ are shown for a variety of forecast users, characterized by their individual cost-loss ratio. It appears that, for all thresholds and indices, valuable forecasts for certain user groups can be produced. Especially riskaverse forecast users with low cost-loss ratios would benefit from ensemble forecasts for events of long duration or high magnitude and severity. In contrast, forecasts of longer, more severe events have no additional value for users with higher cost-loss ratios. These users would benefit from probabilistic forecasts of less intense events. For all users with cost/loss ratios $<0.6$, i.e., especially the risk-averse users, value scores $>50 \%$ are possible. The same evaluation was performed for streamflow drought index forecasts using a higher or lower streamflow drought detection threshold (not shown). In accordance with Fig. 6, higher value scores are possible with the 5th quantile, and lower scores with the 50th quantile as detection threshold. The highest value score for each threshold is reached where the cost-loss ratio concurs with the climatological frequency of the event. This property of the value score is the reason for the shift to the left with increasing thresholds. The maximum of the value score, however, is not strongly dependent on the duration, severity or magnitude of the event and is here reaching values of 0.4 0.6 .

A direct comparison of the forecast quality of streamflow drought indices with the quality of probabilistic daily predictions as shown in Fig. 4 is not possible, as streamflow drought events typically cover several days and no longer contain information about the lead time. The loss of predictive skill of daily probabilistic forecasts with growing lead time has already been addressed (Fig. 4). In comparison, the maximum value score of probabilistic streamflow drought index forecasts is not strongly dependent on the duration, severity or magnitude of the event . As the timing of the streamflow drought events is not exactly specified, but is somewhere between day 1 and day 32, the value score for the events ranges around the lead time averaged value score of the probabilistic daily forecasts as shown in Fig. 4b.

\subsection{Timing}

One drawback when forecasting streamflow drought indices instead of the full hydrograph is the lack of information obtained about the timing of the event. An approach to evaluate this forecast characteristic is to consider timing as the center time between event onset and end of the event or forecast, as described in Sect. 2.3 or Fig. 3. The median of the ensemble of forecast timings is evaluated against the observed timing. Due to the forecast range, the timing is restricted to 32 days, whereas this limit can only by reached by events starting on the last day of the forecast. A concentration of events will have a timing around 16 days, because the longer the event, the closer the timing has to be to the center of the forecast range.

The performance of the forecast system in predicting the timing of events is assessed by having a closer look at the 

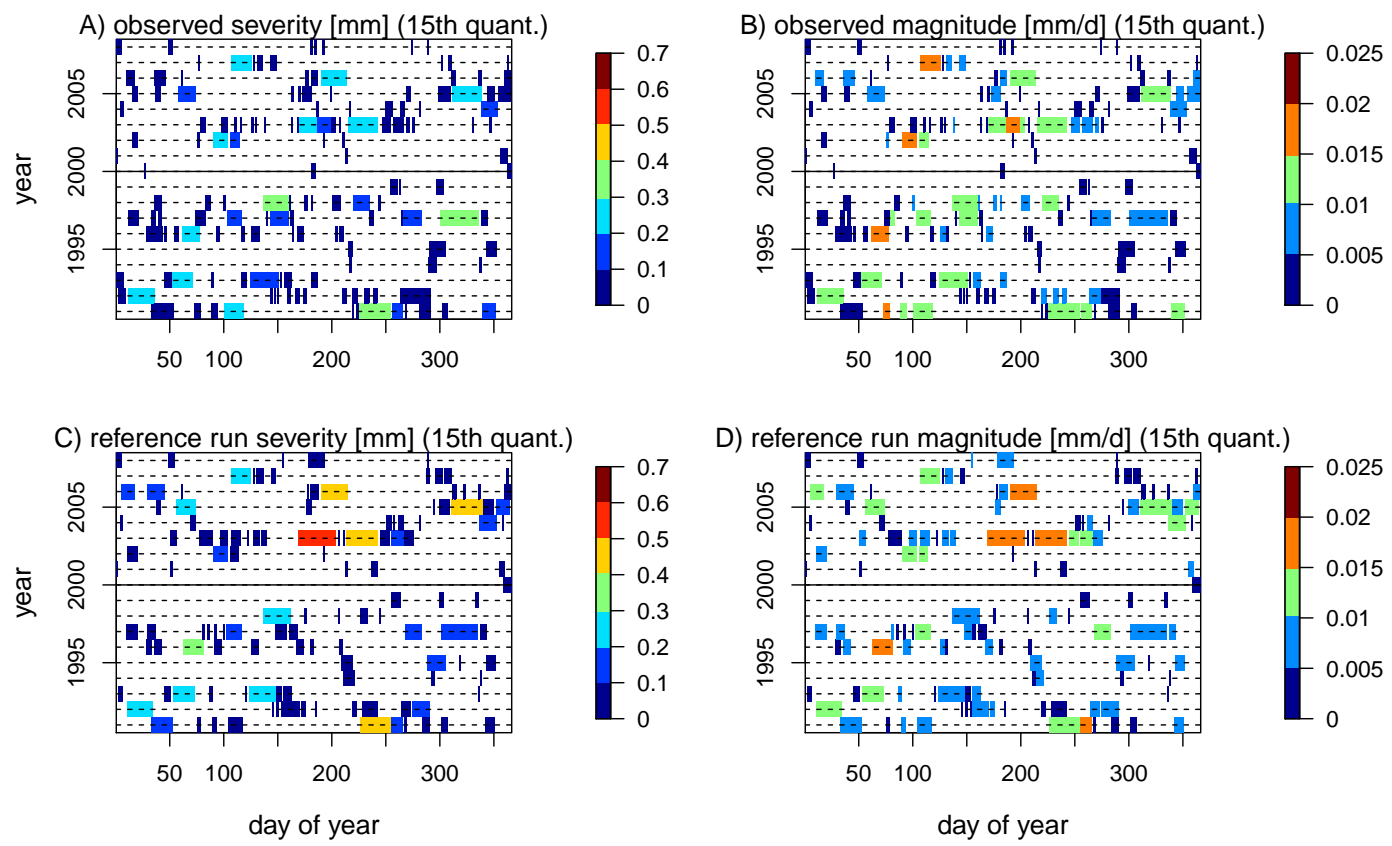

Fig. 7. Periods of streamflow drought occurrence, with severity (A and $\mathbf{C})$ and magnitude (B and $\mathbf{D})$ indicated by colors. (A) and (B) are derived from the observed runoff, while (C) and (D) are derived from the reference run
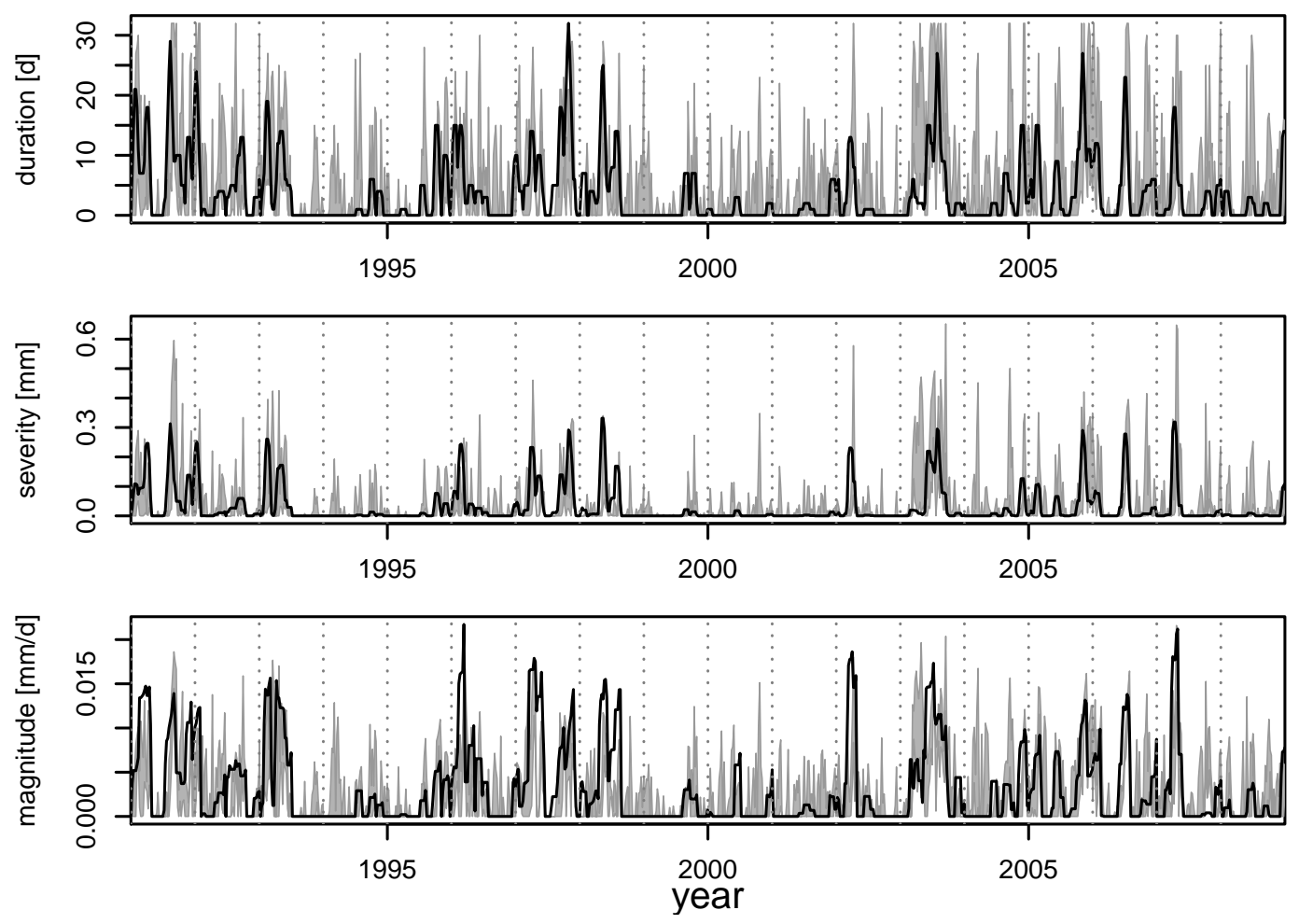

Fig. 8. Concatenation of weekly issued ensemble forecasts of streamflow drought duration, severity and magnitude from the 32-day lead time VarEPS-driven reforecasts (ensemble range shaded in gray), and corresponding observations (black line). The threshold to characterize a streamflow drought event is the varying 15th quantile of runoff. Although the forecasts and observations are not continuous, the data are presented as lines to enhance readability. 

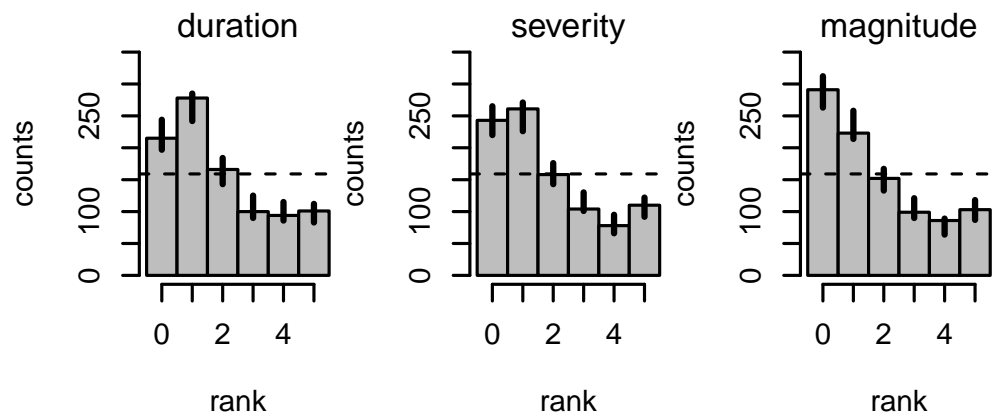

Fig. 9. Rank histograms with $90 \%$ confidence intervals of forecast duration, severity and magnitude. The histogram shows the number of observations attributed to each rank, i.e., the number of times observations lie within the 6 classes formed by the 5-member ensemble forecast. A well-calibrated ensemble prediction system would match the dashed line.
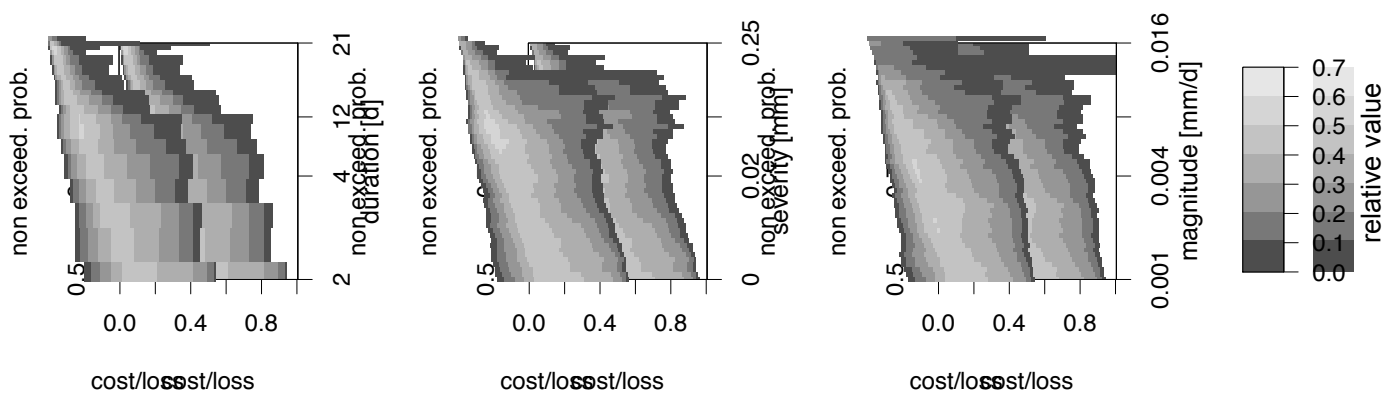

Fig. 10. Relative economic value of Thur ensemble forecasts of streamflow drought duration, magnitude and severity (columns) using the varying 15th quantile of runoff as the streamflow drought detection threshold. The economic value is shaded in gray for forecast users with different cost-loss ratios (x-axis) and for different event thresholds. The left y-axis shows the non-exceedance probability and the right $y$-axis the quantiles for the 50th, 70th, 80th and 95th non-exceedance probability.

cases when a forecast streamflow drought event was observed. Of all forecast events, $46 \%$ had a counterpart in the observations (hit rate), and $32 \%$ were missed or false alarms. Figure 11 shows how the timing of the observed event relates to the ensemble median of the predicted timing for the $42 \%$ of hits. The data exhibit a lot of scatter, but, as underlined by the 2-d density map, the forecast timing can explain $22 \%$ of the variance in the observed timing. In order to attribute a forecast event to an observed event, the events should at least for one day overlap. This is the case for $49 \%$ of all hits.

\section{Discussion and conclusions}

Eighteen years of weekly initialized, hydrological ensemble forecasts of daily mean runoff for the Thur catchment in Switzerland, with a lead time of 32 days, were evaluated. The focus was on their potential to provide skilful, and thus valuable, information about the characteristics of streamflow droughts. The basic assumption of a higher predictability of low flow than peak flow was confirmed by the verification results. This was attributed to the fact that long-lived processes dominate the recession behavior of the runoff. For higher flow, in contrast, the quality of the runoff forecasts is strongly dependent on the correct timing and the amount of precipitation given by the meteorological forcing model, limiting predictability. The positive effect of good initial states on the forecast quality is quickly lost in those cases. This was also confirmed for catchments prone to flash floods, where the influence of initial conditions was found to be already lost after just a few hours (Zappa et al., 2011).

It was further found that, for the predictability of streamflow droughts, a good representation of the hydrological model states at forecast initialization is essential. In a low runoff regime, a good initialization can be beneficial for the forecast for a much longer range. A possible explanation would be that the initial state variables contribute on different time scales to the produced runoff. They therefore determine the recession behavior, which is crucial for the forecast of streamflow drought events. Consequently, good initial states can contribute to forecast quality in a low runoff regime over a longer range. Shukla and Lettenmaier (2011) as well as Singla et al. (2012) similarly stress the importance of the initial conditions for lead times of up to one month, depending on the climatic conditions. In this study, a comparison of the observed runoff with the runoff from a reference run indicated the good quality of the used initial states, legitimating the launch of a subsequent forecast. 


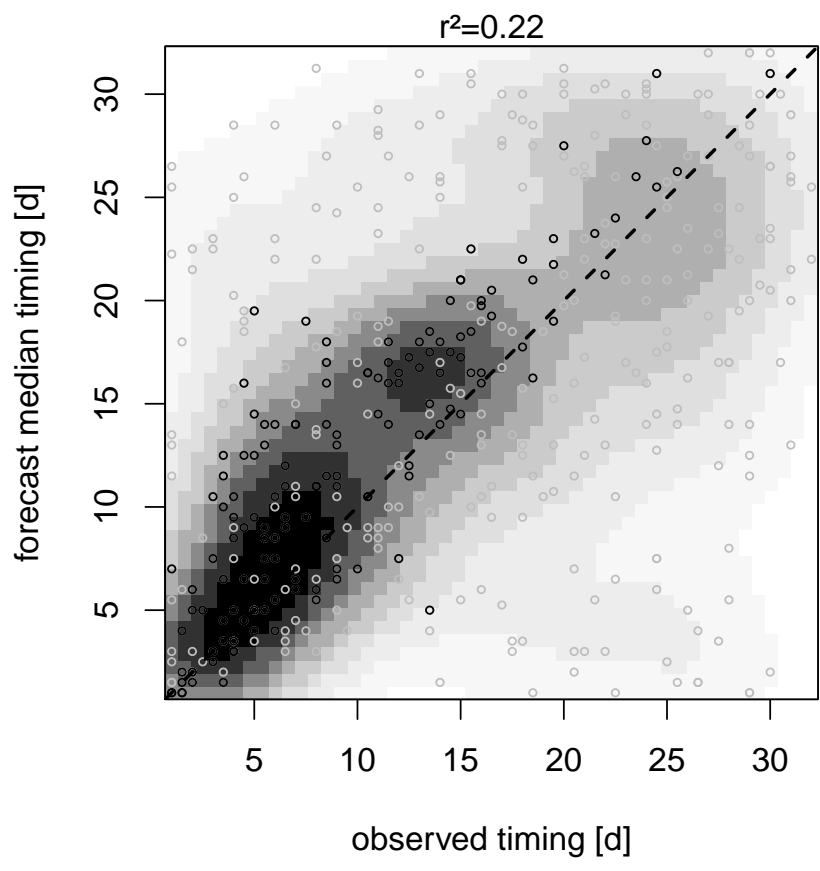

Fig. 11. Observed vs. forecast lead times (median) of streamflow drought events. The center between the onset and offset of an event was chosen as the lead time. The background field is the estimated 2-d density (dimensionless). The black dots mark the events that overlap by at least 1 day with the observed event.

Having ensemble forecasts of the streamflow drought indices duration, severity and magnitude at hand was shown to provide additional value to end users. Using those forecasts results in an economic advantage, mostly independent of the duration, severity or magnitude of the event. Compared to daily forecasts, streamflow drought index forecasts are of reduced complexity, as they no longer contain information about the timing of the streamflow drought event. Hence, the forecast system is less penalized when the onset and offset of streamflow drought events are lagged compared to observations, which enhances the value of the forecasts. It was shown that streamflow drought index forecast can reach economical values greater $50 \%$ for the more risk-averse users. A comparison of the forecast timing of drought events with the observed timing showed that this information gives only a rough estimate. The forecasts of streamflow drought indices can provide useful information about the characteristics of an upcoming event. The timing prediction should, however, be handled with caution.

The ensemble forecasts evaluated in this study were performed for a relatively large alpine catchment. This was chosen mainly in order to ensure the occurrence of longer periods of low streamflow, as in larger catchments runoff is not as strongly affected by small or local precipitation events. However, we also tested streamflow drought predictions for smaller alpine catchments. There, only shorter streamflow drought events could be evaluated and the value of these forecasts was found to be lower. Nevertheless, streamflow drought index forecasts can still be useful for smaller catchments.

When analyzing streamflow droughts on time scales of one month or longer, it is common to apply a smoothing of the observed or forecast streamflow time series. This should prevent counting shorter streamflow depletions as individual drought events, although they belong to the same larger-scale drought. Such a smoothing is not applied in this study as also short-term water shortages of one day can have an economical impact, independent on whether the single events are induced by a larger-scale drought event or not. Sectors prone to short-term streamflow droughts are, e.g., shipping, hydro-power production or power production in general as the cooling of many power plants depends on the availability of river water. Forecast users from those sectors could potentially benefit from forecast of short events, and this study investigates the potential of a hydrometeorological forecast system to predict them.

Further refinements could improve the predictability of streamflow droughts. The parameters of the hydrological model PREVAH were found by optimizing the predicted runoff subject to average flow volume. This is certainly not the best approach for streamflow drought forecasts and might introduce biases in predictions of the lower flow regime. Our findings, however, suggest that an operationally used hydrological prediction system, which is meant to give warnings primarily of peak flow, can without larger modifications also be suitable for forecasting streamflow droughts. Biases due to inadequate model parameterization can be partly addressed by a simple statistical post-processing, e.g., defining the streamflow drought threshold for the observed runoff from an observation climatology and for forecast runoff from past model predictions. More complex methods could be considered, but this was beyond the scope of this study.

The downscaling of the meteorological model could be further improved. In this study, the relatively coarse horizontal grid of the meteorological forcing model was downscaled to the grid of the hydrological model by a simple bilinear interpolation. A dynamic downscaling involving one or more nested regional models would be preferable. However, no such approach was available for the region and the forecast range of one month considered here.

The operational version of the meteorological forcing model VarEPS would offer 51 ensemble members compared to only 5 members from the reforecast. As a low number of ensemble members introduce low reliability in the forecast (Weigel et al., 2007), the here shown verification scores reflect the lower limit of what can be achieved with the full ensemble. Despite the limitations, ensemble forecasts of streamflow drought indices could provide a valuable basis for decision-making and be of economic value for forecast users. 
Acknowledgements. Support from the Swiss National Research Program Sustainable Water Management (NRP 61 project DROUGHT-CH) is gratefully acknowledged. We also express our gratitude to ECMWF and MeteoSwiss for providing the necessary data.

Edited by: A. Gelfan

\section{References}

Beniston, M.: The 2003 heat wave in Europe: A shape of things to come? An analysis based on Swiss climatological data and model simulations, Geophys. Res. Lett., 31, L02202, doi:10.1029/2003GL018857, 2004.

Bergström, S. and Forsman, A.: Developement of a conceptual deterministic rainfall-runoff model, Nord. Hydrol., 4, 147-170, doi:10.2166/nh.1973.012, 1973.

Bordi, I. and Sutera, A.: DROUGHT MONITORING AND FORECASTING AT LARGE SCALE, in: Methods and Tools for Drought Analysis and Management, edited by: Rossi, G., Vega, T., and Bonaccorso, B., Chap. 1, 3-27, Springer Netherlands, doi:10.1007/978-1-4020-5924-7_1, 2007.

Cacciamani, C., Morgillo, A., Marchesi, S., and Pavan, V.: Monitoring and forecasting drought on a regional scale: Emilia-Romagna region, in: Methods and Tools for Drought Analysis and Management, edited by: Rossi, G., Vega, T., and Bonaccorso, B., Chap. 2, 29-48, Springer Netherlands, doi:10.1007/978-1-40205924-7_2, 2007.

Cancelliere, A., Mauro, G. D., Bonaccorso, B., and Rossi, G.: Drought forecasting using the Standardized Precipitation Index, Water Resour. Manag., 21, 801-819, doi:10.1007/s11269-0069062-y, 2006.

Cebrián, A. C. and Abaurrea, J.: Risk measures for events with a stochastic duration: an application to drought analysis, Stoch. Env. Res. Risk A., 26, 971-981, doi:10.1007/s00477-011-05215, 2011.

Chung, C.-H. and Salas, J. D.: Drought Occurrence Probabilities and Risks of Dependent Hydrologic Processes, J. Hydrol. Eng., 5, 259-268, doi:10.1061/(ASCE)1084-0699(2000)5:3(259), 2000.

Cloke, H. L. and Pappenberger, F.: Ensemble flood forecasting: A review, J. Hydrol., 375, 613-626, doi:10.1016/j.jhydrol.2009.06.005, 2009.

Fleig, A. K., Tallaksen, L. M., Hisdal, H., and Demuth, S.: A global evaluation of streamflow drought characteristics, Hydrol. Earth Syst. Sci., 10, 535-552, doi:10.5194/hess-10-535-2006, 2006.

Fleig, A. K., Tallaksen, L. M., Hisdal, H., and Hannah, D. M.: Regional hydrological drought in north-western Europe: linking a new Regional Drought Area Index with weather types, Hydrol. Process., 25, 1163-1179, doi:10.1002/hyp.7644, 2011.

Fundel, F. and Zappa, M.: Hydrological Ensemble Forecasting in Mesoscale Catchments: Sensitivity to Initial Conditions and Value of Reforecasts, Water Resour. Res., 47, 1-15, doi:10.1029/2010WR009996, 2011.

Gurtz, J., Baltensweiler, A., and Lang, H.: Spatially distributed hydrotope-based modelling of evapotranspiration and runoff in mountainous basins, Hydrol. Process., $\quad 13, \quad 2751-2768$, doi:10.1002/(SICI)1099-
1085(19991215)13:17<2751::AIDHYP897>3.3.CO;2-F, 1999.

Heim Jr., R. R.: A Review of Twentieth-Century Drought Indices Used in the United States, B. Am. Meteorol. Soc., 83, 11491165, 2002.

Hirschberg, P. A., Abrams, E., Bleistein, A., Bua, W., Monache, L. D., Dulong, T. W., Gaynor, J. E., Glahn, B., Hamill, T. M., Hansen, J. A., Hilderbrand, D. C., Hoffman, R. N., Morrow, B. H., Philips, B., Sokich, J., and Stuart, N.: A Weather and Climate Enterprise Strategic Implementation Plan for Generating and Communicating Forecast Uncertainty Information, B. Am. Meteorol. Soc., 92, 1651-1666, doi:10.1175/BAMS-D-1100073.1, 2011.

Hisdal, H. and Tallaksen, L. M.: Technical Report to the ARIDE project No. 6 Drought Event Definition, Tech. Rep. 6, University of Oslo, 2000.

Hisdal, H., Stahl, K., Tallaksen, L. M., and Demuth, S.: Have streamflow droughts in Europe become more severe or frequent?, Int. J. Climatol., 21, 317-333, doi:10.1002/joc.619, 2001.

Hwang, Y. and Carbone, G. J.: Ensemble Forecasts of Drought Indices Using a Conditional Residual Resampling Technique, J. Appl. Meteorol. Clim., 48, 1289-1301, doi:10.1175/2009JAMC2071.1, 2009.

Jaun, S. and Ahrens, B.: Evaluation of a probabilistic hydrometeorological forecast system, Hydrol. Earth Syst. Sci., 13, 10311043, doi:10.5194/hess-13-1031-2009, 2009.

Kim, T.-W. and Valdés, J. B.: Nonlinear Model for Drought Forecasting Based on a Conjunction of Wavelet Transforms and Neural Networks, J. Hydrol. Eng., 8, 319-328, doi:10.1061/(ASCE)1084-0699(2003)8:6(319), 2003.

Kirchner, J. W.: Catchments as simple dynamical systems: Catchment characterization, rainfall-runoff modeling, and doing hydrology backward, Water Resour. Res., 45, 1-34, doi:10.1029/2008WR006912, 2009.

Li, H., Luo, L., and Wood, E. F.: Seasonal hydrologic predictions of low-flow conditions over eastern USA during the 2007 drought, Atmos. Sci. Lett., 9, 61-66, doi:10.1002/asl.182, 2008.

Lohani, V. K. and Loganathan, G. V.: An early warning system for drought management using the palmer drought index, J. Am. Water Resour. As., 33, 1375-1386, doi:10.1111/j.17521688.1997.tb03560.x, 1997.

Luo, L. and Wood, E. F.: Monitoring and predicting the 2007 U.S. drought, Geophys. Res. Lett., 34, 1-6, doi:10.1029/2007GL031673, 2007.

Mason, S. J. and Weigel, A. P.: A Generic Forecast Verification Framework for Administrative Purposes, Mon. Weather Rev., 137, 331-349, doi:10.1175/2008MWR2553.1, 2009.

Mishra, A. K. and Desai, V. R.: Drought forecasting using stochastic models, Stoch. Env. Res. Risk A., 19, 326-339, doi:10.1007/s00477-005-0238-4, 2005.

Mishra, A. K. and Desai, V.: Drought forecasting using feedforward recursive neural network, Ecol. Modell., 198, 127-138, doi:10.1016/j.ecolmodel.2006.04.017, 2006.

Mishra, A. K. and Singh, V. P.: A review of drought concepts, J. Hydrol., 391, 202-216, doi:10.1016/j.jhydrol.2010.07.012, 2010.

Moreira, E., Coelho, C., Paulo, A., Pereira, L., and Mexia, J.: SPIbased drought category prediction using loglinear models, J. Hydrol., 354, 116-130, doi:10.1016/j.jhydrol.2008.03.002, 2008. 
Morid, S., Smakhtin, V., and Bagherzadeh, K.: Drought forecasting using artificial neural networks and time series of drought indices, Int. J. Climatol., 27, 2103-2111, doi:10.1002/joc.1498, 2007.

Murphy, A. H.: The Value of Climatological, Categorical and Probabilistic Forecasts in the Cost-Loss Ratio Situation, Mon. Weather Rev., 105, 803-816, doi:10.1175/15200493(1977)105<0803:TVOCCA > 2.0.CO;2, 1977.

Nalbantis, I. and Tsakiris, G.: Assessment of Hydrological Drought Revisited, Water Resour. Manag., 23, 881-897, doi:10.1007/s11269-008-9305-1, 2008.

Nash, J. and Sutcliffe, J.: River flow forecasting through conceptual models Part I - A discussion of principles, J. Hydrol., 10, 282290, doi:10.1016/0022-1694(70)90255-6, 1970.

Özger, M., Mishra, A. K., and Singh, V. P.: Long Lead Time Drought Forecasting Using a Wavelet and Fuzzy Logic Combination Model: A Case Study in Texas, J. Hydrometeorol., 13, 284-297, doi:10.1175/JHM-D-10-05007.1, 2012.

Richardson, D. S.: Skill and relative economic value of the ECMWF ensemble prediction system, Q. J. Roy. Meteor. Soc., 126, 649667, doi:10.1002/qj.49712656313, 2000.

Rings, J., Vrugt, J. A., Schoups, G., Huisman, J. A., and Vereecken, H.: Bayesian model averaging using particle filtering and Gaussian mixture modeling: Theory, concepts, and simulation experiments, Water Resour. Res., 48, W05520, doi:10.1029/2011WR011607, 2012.

Roulin, E.: Skill and relative economic value of medium-range hydrological ensemble predictions, Hydrol. Earth Syst. Sci., 11, 725-737, doi:10.5194/hess-11-725-2007, 2007.

Schär, C., Vidale, P. L., Lüthi, D., Frei, C., Häberli, C., Liniger, M. A., and Appenzeller, C.: The role of increasing temperature variability in European summer heatwaves, Nature, 427, 332336, doi:10.1038/nature02300, 2004.

Shukla, S. and Lettenmaier, D. P.: Seasonal hydrologic prediction in the United States: understanding the role of initial hydrologic conditions and seasonal climate forecast skill, Hydrol. Earth Syst. Sci., 15, 3529-3538, doi:10.5194/hess-15-35292011, 2011.

Singla, S., Céron, J.-P., Martin, E., Regimbeau, F., Déqué, M., Habets, F., and Vidal, J.-P.: Predictability of soil moisture and river flows over France for the spring season, Hydrol. Earth Syst. Sci., 16, 201-216, doi:10.5194/hess-16-201-2012, 2012.

Smakhtin, V.: Low flow hydrology: a review, J. Hydrol., 240, 147186, doi:10.1016/S0022-1694(00)00340-1, 2001.

Steinemann, A. C.: Using Climate Forecasts for Drought Management, J. Appl. Meteorol. Clim., 45, 1353-1361, doi:10.1175/JAM2401.1, 2006.

Tadesse, T., Wilhite, D. A., Hayes, M. J., Harms, S. K., and Goddard, S.: Discovering Associations between Climatic and Oceanic Parameters to Monitor Drought in Nebraska Using Data-Mining Techniques, J. Climate, 18, 1541-1550, doi:10.1175/JCLI3346.1, 2005.

Talagrand, O., Vautard, R., and Strauss, B.: Evaluation of probabilistic prediction systems, in: Proc. ECMWF Workshop on Predictability, 1-25, ECMWF, Reading, Berkshire RG2 9AX, UK, 1997.

Tallaksen, L. M., Madsen, H., and Clausen, B.: On the definition and modelling of streamflow drought duration and deficit volume, Hydrolog. Sci. J., 42, 15-33, doi:10.1080/02626669709492003,
1997.

van Ogtrop, F. F., Vervoort, R. W., Heller, G. Z., Stasinopoulos, D. M., and Rigby, R. A.: Long-range forecasting of intermittent streamflow, Hydrol. Earth Syst. Sci., 15, 3343-3354, doi:10.5194/hess-15-3343-2011, 2011.

Vidal, J.-P., Martin, E., Franchistéguy, L., Habets, F., Soubeyroux, J.-M., Blanchard, M., and Baillon, M.: Multilevel and multiscale drought reanalysis over France with the Safran-Isba-Modcou hydrometeorological suite, Hydrol. Earth Syst. Sci., 14, 459-478, doi:10.5194/hess-14-459-2010, 2010.

Vitart, F., Bonet, A., Alonso Balmaseda, M., Balsamo, G., Bidlot, J.-R., Buizza, R., Fuentes, M., Hofstadler, A., Molteni, F., and Palmer, T. N.: Merging VarEPS with the monthly forecasting system: a first step towards seamless prediction, ECMWF Newsletter, 115, 35-44, 2008a.

Vitart, F., Buizza, R., Alonso Balmaseda, M., Balsamo, G., Bidlot, J.-R., Bonet, A., Fuentes, M., Hofstadler, A., Molteni, F., and Palmer, T. N.: The new VarEPS-monthly forecasting system: A first step towards seamless prediction, Q. J. Roy. Meteorol. Soc., 134, 1789-1799, doi:10.1002/qj.322, 2008b.

Viviroli, D. and Gurtz, J.: The Hydrological Modelling System Part II - Physical Model Description, Tech. rep., Institute of Geography, University of Berne, Geographica Bernensia P40, Berne, 2007.

Viviroli, D., Zappa, M., Gurtz, J., and Weingartner, R.: An introduction to the hydrological modelling system PREVAH and its preand post-processing-tools, Environ. Modell. Softw., 24, 12091222, doi:10.1016/j.envsoft.2009.04.001, 2009.

Webster, P. J., Jian, J., Hopson, T. M., Hoyos, C. D., Agudelo, P. A., Chang, H.-R., Curry, J. A., Grossman, R. L., Palmer, T. N., and Subbiah, A. R.: Extended-Range Probabilistic Forecasts of Ganges and Brahmaputra Floods in Bangladesh, B. Am. Meteorol. Soc., 91, 1493-1514, doi:10.1175/2010BAMS2911.1, 2010.

Weigel, A. P. and Mason, S. J.: The Generalized Discrimination Score for Ensemble Forecasts, Mon. Weather Rev., 139, 30693074, doi:10.1175/MWR-D-10-05069.1, 2011.

Weigel, A. P., Liniger, M. A., and Appenzeller, C.: The Discrete Brier and Ranked Probability Skill Scores, Mon. Weather Rev., 135, 118-124, doi:10.1175/MWR3280.1, 2007.

Wood, A. W., Maurer, E. P., Kumar, A., and Lettenmaier, D. P.: Long-range experimental hydrologic forecasting for the eastern United States, J. Geophys. Res., 107, 1-15, doi:10.1029/2001JD000659, 2002.

Yoo, J., Kwon, H.-H., Kim, T.-W., and Ahn, J.-H.: Drought frequency analysis using cluster analysis and bivariate probability distribution, J. Hydrol., 420-421, 102-111, doi:10.1016/j.jhydrol.2011.11.046, 2011.

Zaidman, M. D., Rees, H. G., and Young, A. R.: Spatio-temporal development of streamflow droughts in north-west Europe, Hydrol. Earth Syst. Sci., 6, 733-751, doi:10.5194/hess-6-733-2002, 2002.

Zappa, M. and Kan, C.: Extreme heat and runoff extremes in the Swiss Alps, Nat. Hazards Earth Syst. Sci., 7, 375-389, doi:10.5194/nhess-7-375-2007, 2007.

Zappa, M., Jaun, S., Germann, U., Walser, A., and Fundel, F.: Superposition of three sources of uncertainties in operational flood forecasting chains, Atmos. Res., 100, 246-262, doi:10.1016/j.atmosres.2010.12.005, 2011. 